


\section{DISCLAIMER}

This report was prepared as an account of work sponsored by an agency of the United States Government. Neither the United States Government nor any agency Thereof, nor any of their employees, makes any warranty, express or implied, or assumes any legal liability or responsibility for the accuracy, completeness, or usefulness of any information, apparatus, product, or process disclosed, or represents that its use would not infringe privately owned rights. Reference herein to any specific commercial product, process, or service by trade name, trademark, manufacturer, or otherwise does not necessarily constitute or imply its endorsement, recommendation, or favoring by the United States Government or any agency thereof. The views and opinions of authors expressed herein do not necessarily state or reflect those of the United States Government or any agency thereof. 


\section{DISCLAIMER}

Portions of this document may be illegible in electronic image products. Images are produced from the best available original document. 


\section{DISCLAIMER}

This report was prepared as an account of work sponsored by the United States Government. Neither the United States nor the United States Department of Energy, nor any of their employees, makes any warranty, express or implied, or assumes any legal liability or responsibility for the accuracy, completeness, or usefulness of any information, apparatus, product, or process disclosed, or represents that its use would not infringe privately owned rights. Reference herein to any specific commercial product, process, or service by trade name, mark, manufacturer, or otherwise, does not necessarily constitute or imply its endopsemeni, lecommendation, or favoring hy the United States Government or any agency thereof. The views and opinions of authors expressed herein do not necessarily state or reflect those of the United States Government or any agency thereof.

This report was printed from the best available copy.

\begin{tabular}{|c|c|}
\hline $\begin{array}{r}\text { Printed in the Ut } \\
\text { Avai } \\
\text { National Technic } \\
\text { United States De } \\
5285 \text { Po } \\
\text { Springtiel }\end{array}$ & $\begin{array}{l}\text { d States of America } \\
\text { le from } \\
\text { information Service } \\
\text { iment of Commerce } \\
\text { loyal Road } \\
\text { /irginia 22151 }\end{array}$ \\
\hline rice: Printed Copy & ; Microfiche $\$ 3.00$ \\
\hline -Pages & $\begin{array}{c}\text { NTIS } \\
\text { Selling Price }\end{array}$ \\
\hline $001-025$ & 54.00 \\
\hline $026-050$ & $\$ 4.50$ \\
\hline $051-075$ & $\$ 5.25$ \\
\hline $076-100$ & $\$ 6.00$ \\
\hline $101-125$ & $\$ 6.50$ \\
\hline $126-150$ & 57.25 \\
\hline 151.175 & $\$ 8.00$ \\
\hline $176-200$ & 39.00 \\
\hline 201.725 & $\$ 9.25$ \\
\hline $226-250$ & $\$ 9.50$ \\
\hline 231.205 & $\$ 10.75$ \\
\hline $276-300$ & $\$ 11.00$ \\
\hline
\end{tabular}


DEVELOPMENT OF AN

8 KW WIND TURBINE GENERATOR

FOR RESIDENTIAL TYPE APPLICATIONS

Phase I - Design and Analysis

Voiume I - Executive Summary

June 25, 1979

M.C. Cheney, et. al.

Prepared by

United Technologies Research Center

East Hartford, Connecticut 06108.

Tor

Rockwell International Corporation

Energy Systems Group

- Rocky Flats Plant

Wind Systems Program

P.0. Box 464

Golden, Colorado 80401

Subcontract PF68186 F

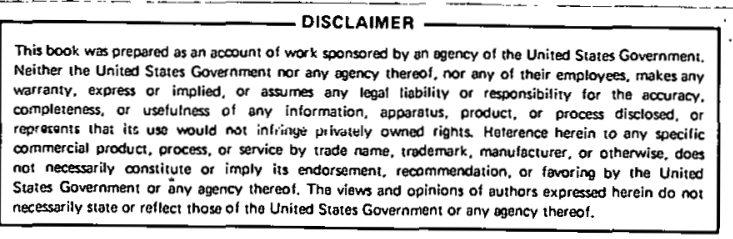

As part of the

UNITED STATES DEPARTMENT OF ENERGY

DIVISION OF DISTRIBUTED SOLAR TECHNOLOGY

FEDERAL WIND ENERGY PROGRAM

Contract No. DE-ACO4-76DP03533

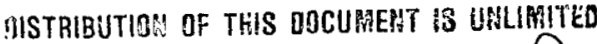




\title{
EXECUTIVE SIMMARY
}

\author{
INTRODUCTION
}

The Composite Bearingless Wind Turbine was developed at the United Technologies Research Center following many years of bearingless rotor research and development for helicopter applications. Wind turbine applications of this rotor concept were initiated in 1975 under an ERDA contract and subsequently a DOE design contract in 1976. The current $8 \mathrm{~kW}$ contract was begun in October 1977 with delivery of the prototype scheduled for November 1979. The contract consists of two phases. Phase I encompasses the complete design of the system and supporting analytical and experimental ștudies. The Phase I final report has been completed, and this executive summary highlights the principal findings described in that report. Phase II consists of fabrication and test, and eventually the delivery of the prototype to Rocky Flats for field evaluation. The completion of this last activity under the contract is expected in mid 1980 at which time a Phase II final report will be issued.

\section{CONCEPT DESCRIPTION}

The composite bearingless wind turbine was made possible by employing the specialized features of the Composite Bearingless Rotor (CBR), developed initially for helicopter application. The composite bearingless rotor evolved as a result of the unique application of fiber reinforced composite materials. The nonisotropic nature of unidirectional composites, generally considered an undesirable feature, yields a structure which is decidedly softer in torsion than in a direction which loads the fibers axially. By employing a finite length of this material at the blade root, torsional deflections can be achieved to satisfy the pitch angle change requirements of a helicopter rotor or wind turbine while providing sufficient stiffness in the in-plane and out-of-plane directions to satisfy hingeless rotor frequency requirements.

A general overview of the UTRC wind turbine is shown in Fig. 1, and a schematic of the basic components of the system are shown in Fig. 2. The blade is comprised of two distinct parts. The outer, or aerodynamic, portion of the blade is fabricated from fiberglass using a pultrusion process. The inner portion of the blade, called the flexbeam, is made up of unidirectional graphite epoxy. The dimensions of the flexbeam are dictated by the edgewise and flatwise frequency requirements, and the required torsional properties are determined 


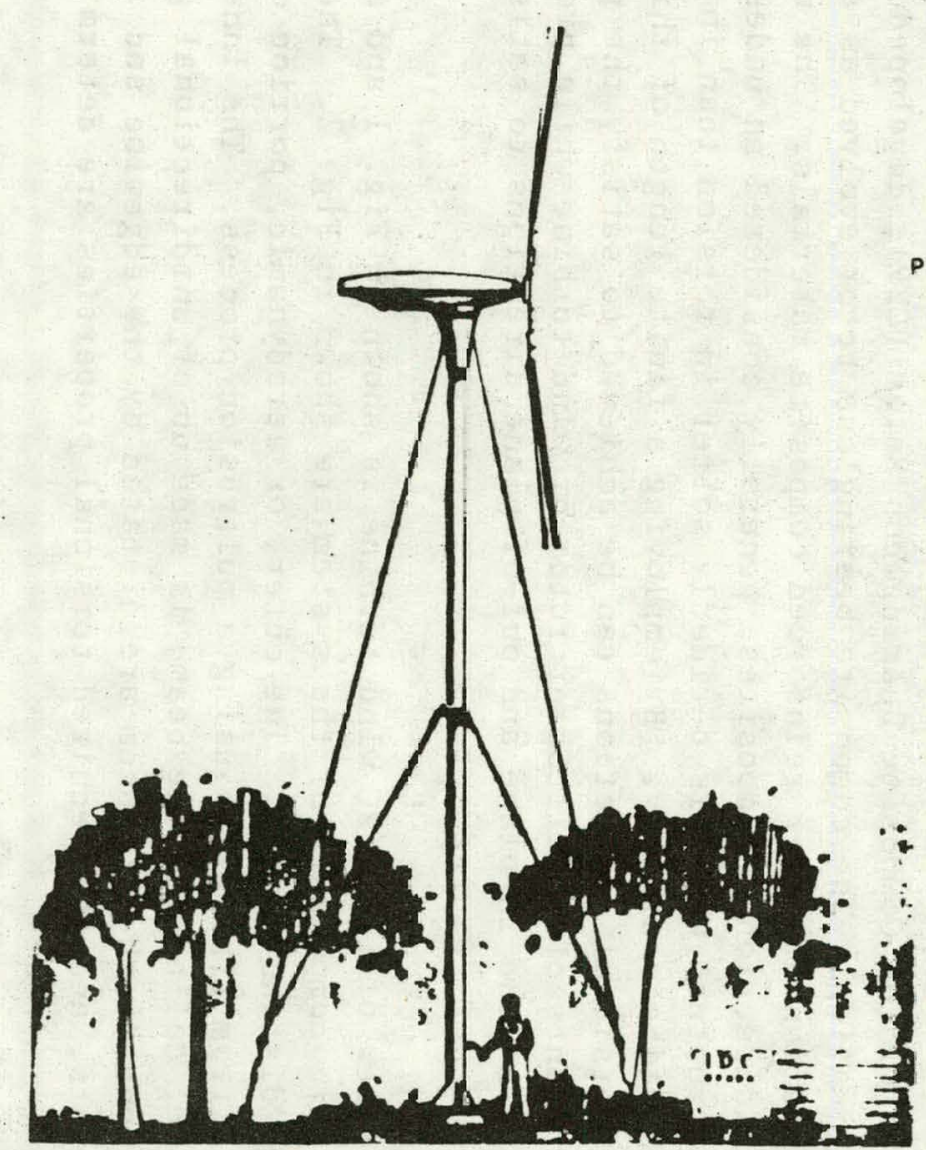

Fig. 1 UTRC Wind Turbine

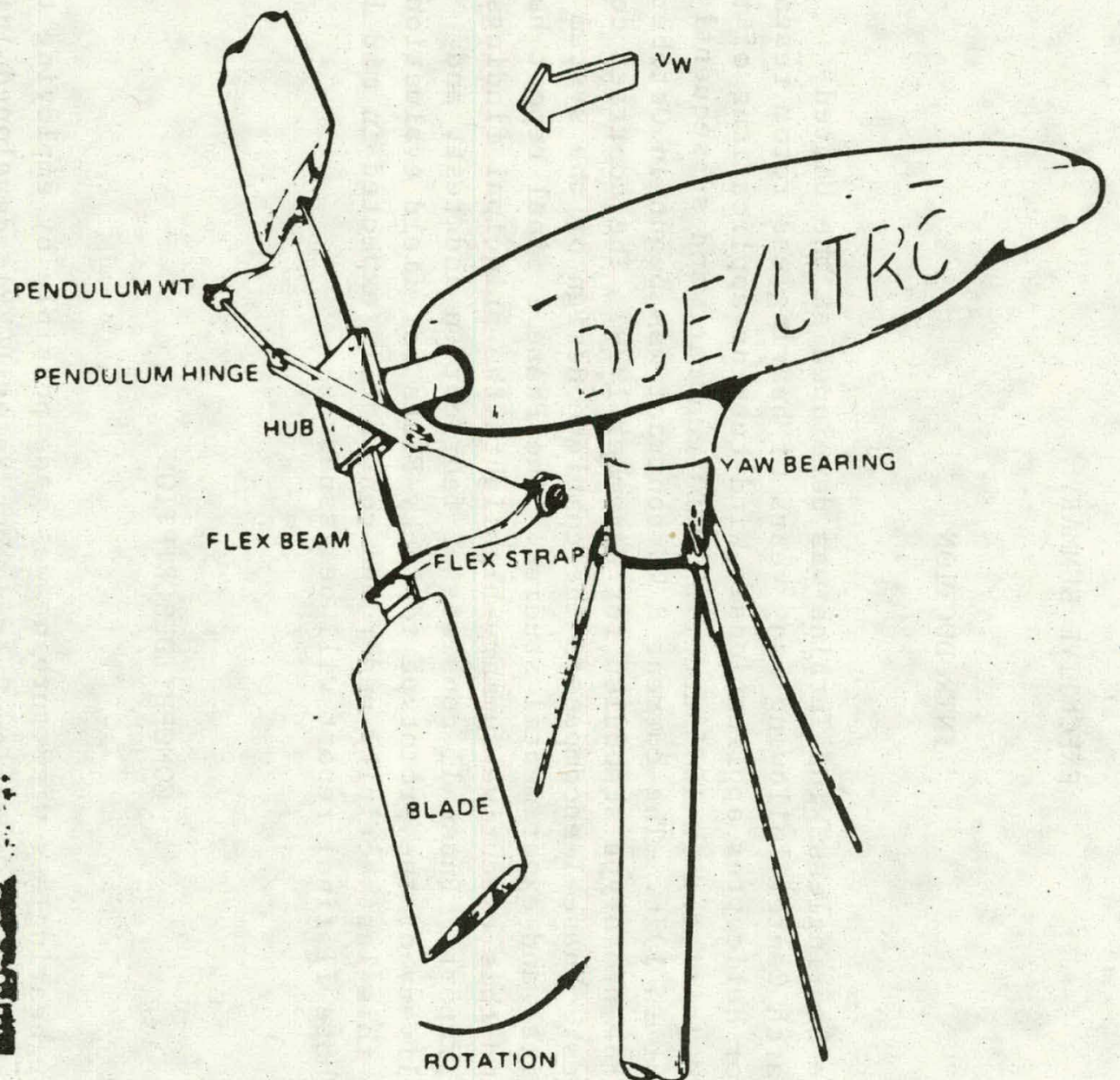

Fig. 2 Wind Turbone Components 
from the pendulum control system. The free length of the flexbeam runs from the hub to approximately 20 percent of the radius where it is joined to the fiberglass blade. As shown in Fig. 2 the outer portion of the flexbeam is connected to the pendulum through a steel strap, called the flexstrap. The flexbeam is layed up and cured in a preconed and pretwisted configuration, and extends through the hub and is connected to the opposite blade in a similar fashion. The flexbeam is pretwisted -16 degrees (leading edge into the wind) to place the blade in a position for self-starting. In this static condition the pendula are coned into the tower approximately 45 degrees by virtue of. their connection to the flexbeam through the flexstraps. For optimum performance it has been shown that the blade pitch angle should operate in the vicinity of \pm 2 degrees. This is achieved by virtue of the pendula acting under the influence of centrifugal force as ipm increases. The pendula begin to move towards the plane of rotation and, through the flexstrap connections to the flexbeam, provide a moment to the blades which twist the flexbeam thereby increasing the blade pitch. The pendula, acting against the torsional spring of the flexbeam, are always in moment equilibrium with the flexbeam.

The self-aligning featurc of the $C B R$ wind turbine results from the inherent dynamic response characteristics of low stiffness hingeless rotors. This arises from the phase lag of a simple spring mass damper system, wherein the mass experiences a finite lag between the time of excitation and the time of response. The duration of the $\mathrm{lag}$ is a function of the frequency and damping of the system. In the case of the wind turbine, which is yawed at an angle to the wind direction, the excitation results from the higher dynamic pressure of the blade rotating into the wind as compared to the blade moving away from the wind: These blades would be in their vertical positions when experiencing the greatest difference in lift. Their maximum flatwise deflection would occur at some position during. the next quarter of a.revolution. This in turn would produce a moment at the blade root which feeds directly into the hub. The turbine would respond to this moment and yaw in a direction to eliminate the differential lifts on the advancing and retreating blades. The motion would end when the blades arc: at equal lift which occurs generally when the turbine axis is aligned with the wind. In a frue yawing system, such as that used for the $\mathrm{CBR}$ wind turbine, any wind direction change would create advancing and retreating blades and therefore the turbine would continuously self-align.

Under high wind speed conditions the wind turbine rotational speed would increase in proportion to wind speed if the pitch angle were left at its optimum value of $t 2$ degrees. This would result in excessive tip speeds and thrust levels which, could potentially lead to a blade failure. Also, as RPM increases it will approach the blade edgewise frequency which would result in a coalescence with the one-per-rev gravity excitation creating a potential instability. The problem of overspeeding has been solved by producing stall on the rotor blades at a specific combination of wind speed and rpm. At a tip speed of approximately 
$122 \mathrm{~m} / \mathrm{s}(400 \mathrm{f} / \mathrm{s})$ which is approximately double the design rpm, the pendula will be essentially in the plane of rotation and produce a pitch angle on the blades of approximately five degrees. This angle, in combination to the aerodynamic angle produced by the wind speed, is sufficient to stall the blades. At this point the rotor tip speed is reduced and adjusts itself to a lower equilibrium which is approximately $90 \mathrm{~m} / \mathrm{s}(300 \mathrm{f} / \mathrm{s})$. The centrifugal force remains sufficiently high at this rpm to assist the blade in counteracting the root moment caused by blade thrust. The rotor will remain stalled until the wind speed drops below the stall point which is estimated to occur at approximately $22 \mathrm{~m} / \mathrm{s}$ ( $50 \mathrm{mph}$ ).

\section{Performance}

A rotor diameter of $9.4 \mathrm{~m}(31 \mathrm{ft})$ was selected, producing more than the required $8 \mathrm{~kW}$ at $9 \mathrm{~m} / \mathrm{s}$ wind speed, and also providing adequate residential power (approximately $2 \mathrm{~kW}$ ) at low wind speeds $(5.4 \mathrm{~m} / \mathrm{s}$ ), more typical of most residential areas. Performance was calculated for two rotor speeds, representing two different gearbox step-up ratios. The user would select the racio dependlng upon whether he had high or low winds. The power output of the rotor for the two speeds is shown in Fig. 3, and the annual energy output is shown in Fig. 4. These results are for operation in conjunction with a utility where the induction generator operates at constant speed. The induction generator could be substituted with an alternator or a dc generator for stand-alone operation, however in this case the rotor speed would vary with wind speed and wuld produce de or variable ac electricity. To obtain 60 cycle ac in this case an inverter would be necessary. A summary of the principal design parameters and performance characteristics are presented in the following table.

$\begin{array}{ll}\text { Rotor diameter } & 9.4 \mathrm{~m}(31 \mathrm{ft}) \\ \text { Number of blades } & 2 \\ \text { Chord } & 0.38 \mathrm{~m}(15 \mathrm{in}) \\ \text { Twist \& taper } & 0 \\ \text { Pre-cone } & 8 \mathrm{deg} \\ \text { Airfoil } & \mathrm{N} A C A 23112 \\ \text { Rated Wind Speed } & 9 \mathrm{~m} / \mathrm{s}(20 \mathrm{mph}) \\ \text { Tip speed (low wind } & 53.3 \mathrm{~m} / \mathrm{s}(175 \mathrm{f} / \mathrm{s}) \\ \quad \text { speed gearbox) } & 15 \mathrm{~kW} \mathrm{induction} \mathrm{type} \\ \text { Generator } & 9.5 \mathrm{~kW} \\ \text { Power at } 9 \mathrm{~m} / \mathrm{s} & 23,000 \mathrm{kWh} \\ \text { Annual power output } & \\ \quad \text { at } 5.4 \mathrm{~m} / \mathrm{s} & 4 \mathrm{~m} / \mathrm{s}(9 \mathrm{mph}) \\ \text { Cut-in wind speed } & 35 \mathrm{~m} / \mathrm{s} \text { ( } 78 \mathrm{mph}) \\ \text { Cut-out wind speed } & \end{array}$




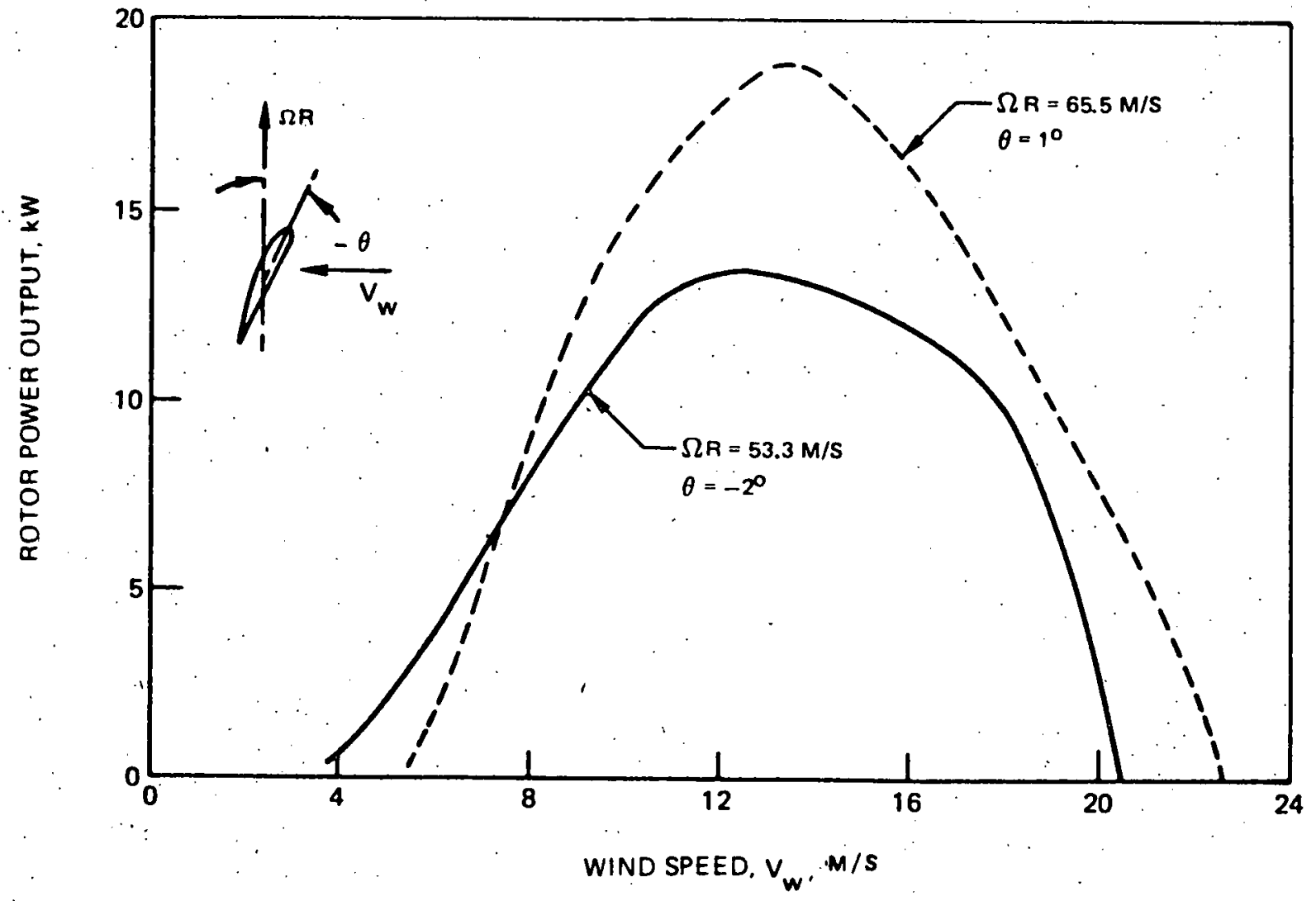

Fig. 3 Rotor Power Output

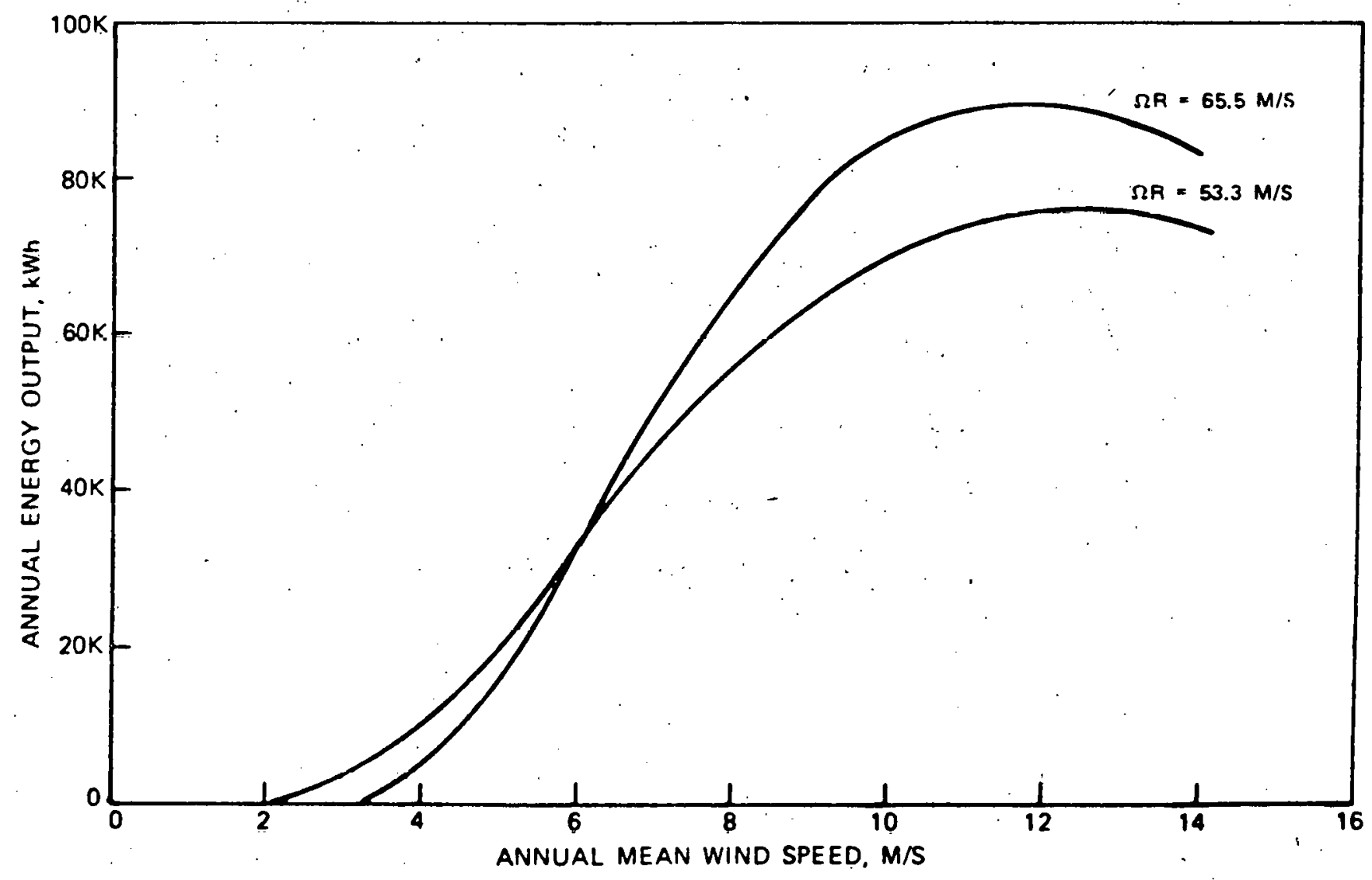

Fig. 4 Annual Energy Output 
Various trade-off studies were conducted to optimize the final prototype configuration. These studies examined parameters such as number of blades, diameter, solidity, blade construction, bending frequencies, generator type, gearbox ratio, and tower design. The primary objective of the design study was to achieve a design which had the potential for low production cost but also would minimize the technical risks of the prototype machine. When compromises were necessary, conservative decisions were generally made to enhance the success of the prototype.

\section{Rotor and Pendulum}

The rotor blade consists of an inboard flexbeam, spanning about 17 percent of the radius and carrying through the hub to the opposite blade, and an outboard airfoil region which produces the aerodynamic driving torque. The blade pitch control is derived from the pendulum motion through the flexstrap connection as described in the Concept Description section. The arrangement is shown in Fig. 5. The flexbeam is made up from unidirectional graphite/epoxy and is attached to the blade by means of an aluminum cuff. The blade itself is 100 percent fiberglass and is fabricated using a pultrusion process. The pultrusion technique was selected due to its potential for very low production costs.

\section{Power Components}

The main frame consists of a steel weldment with the various components mechanically attached. A schematic of the design is shown in Fig. 6. The main rotor shaft is supported at either end with roller bearings and drives the 2-stage step-up transmission through a flexible coupling. The transmission is base mounted to the main frame and the generator is C-face mounted to the transmission. A speed switch is provided, as shown, to connect and disconnect the grid at preselected shaft speeds. The system is free in yaw and supported through two roller bearings held within the lower cavity. Power and temporary instrumentation signals are transmited through sliprings attached below the yaw bearings. A fiberglass fairing, consisting of three molded panels, provides weather protection for the power components. 


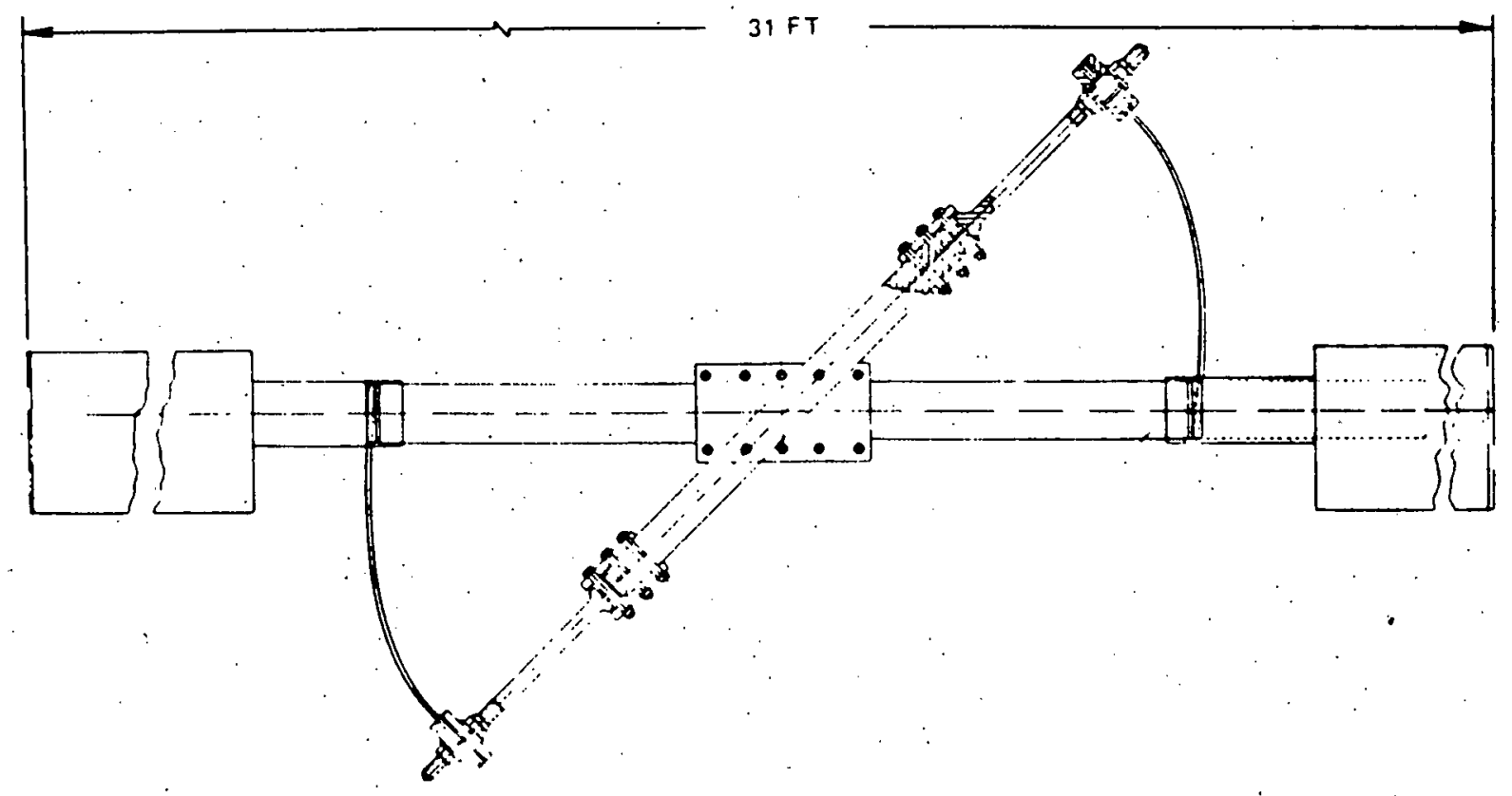

Fig. 5 Hub \& Pendulum Assembly

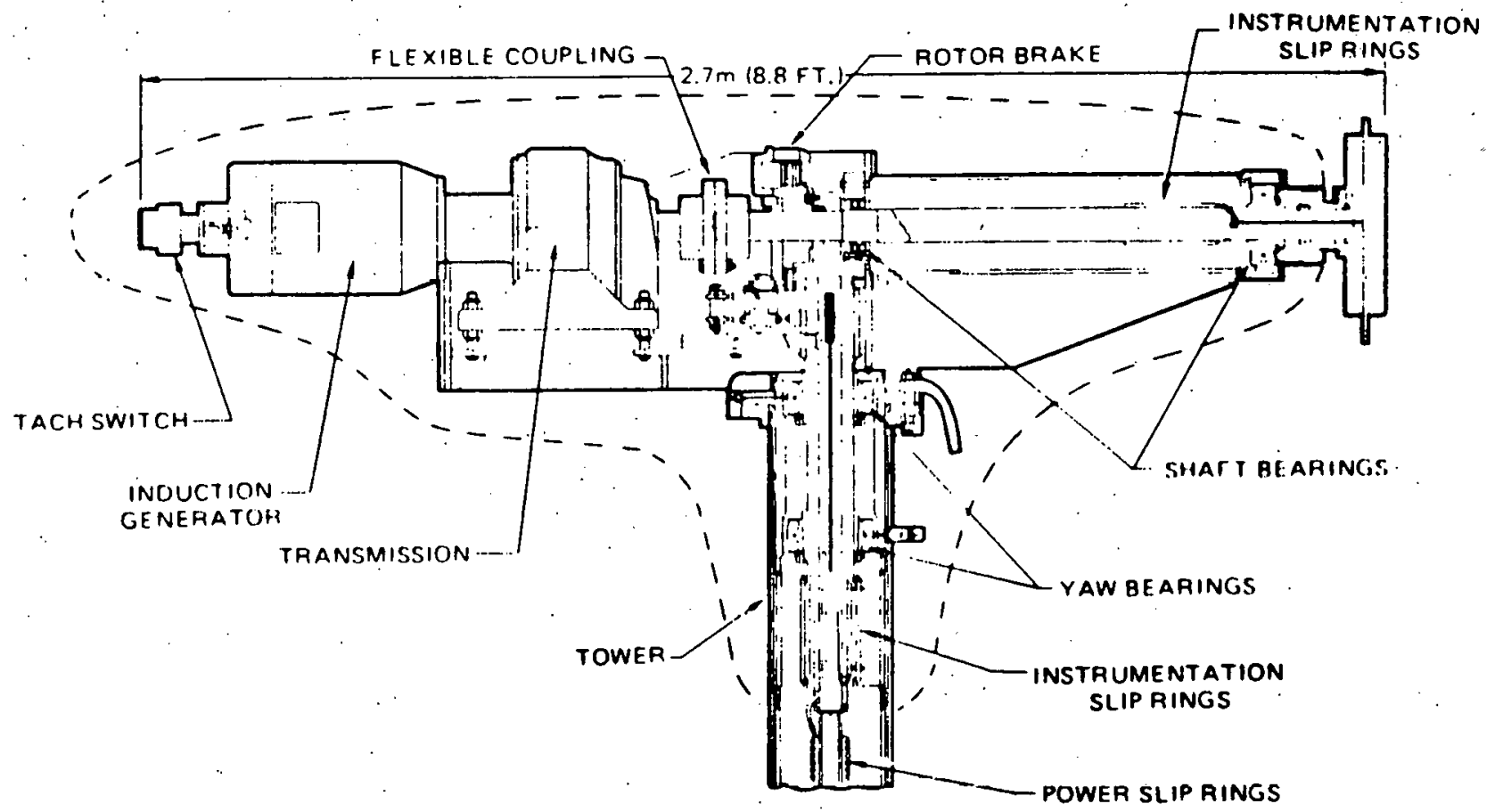

Fig. 6 Nacelle Components 
The tower consists of two $26 \mathrm{ft}$ sections of $11 \mathrm{in.} 0 . \mathrm{D} .1 / 4 \mathrm{in}$. wall steel pipe with a heavy baseplate welded at one end and slip-on flanges welded at the other free ends. The center flanges are bolted together and provide the attachment for the lower guy wires, and the upper flange is mated with the flange holding the yaw bearings and also provides the attachment for the upper guy wires. Tower erection is achieved through the use of a gin pole and an 8000 . 1 b capacity winch. The tower and erection procedure is shown schematically. in Fig. 7 .

\section{ESTIMATED PRODUCTION COSTS}

A detailed estimate of the total system cost is presented in the Phase I report. Assumptions in the estimate include: 1977 dollars, production rate of 1000 units per year, burdened labor rate of $12 \$ / h r$, and a mark-up of 40 percent on all materials and purchased parts. The following table summarizes the major component costs.

Cost Summary

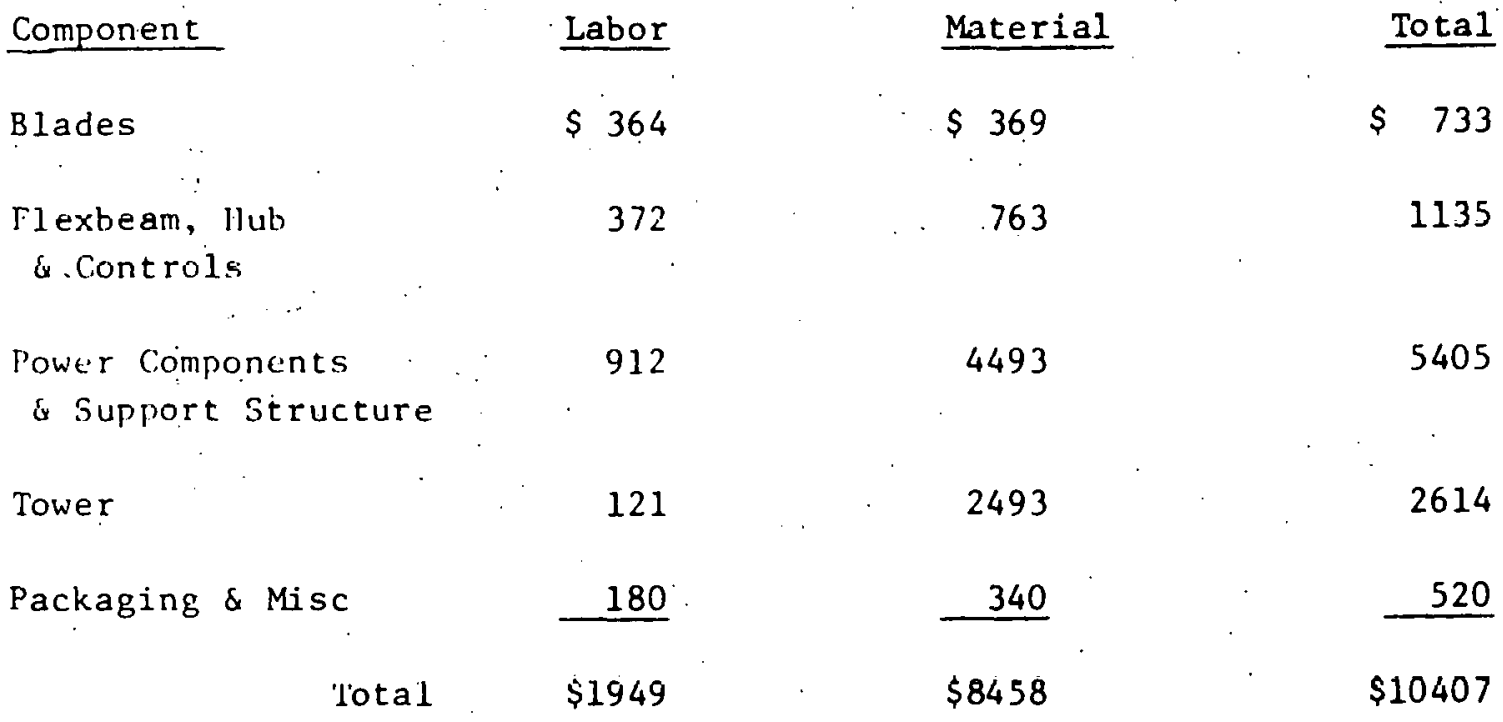

Additional costs which one must incur before the system becomes operational are shipping and installation. These are expected to add 15-20 percent. 


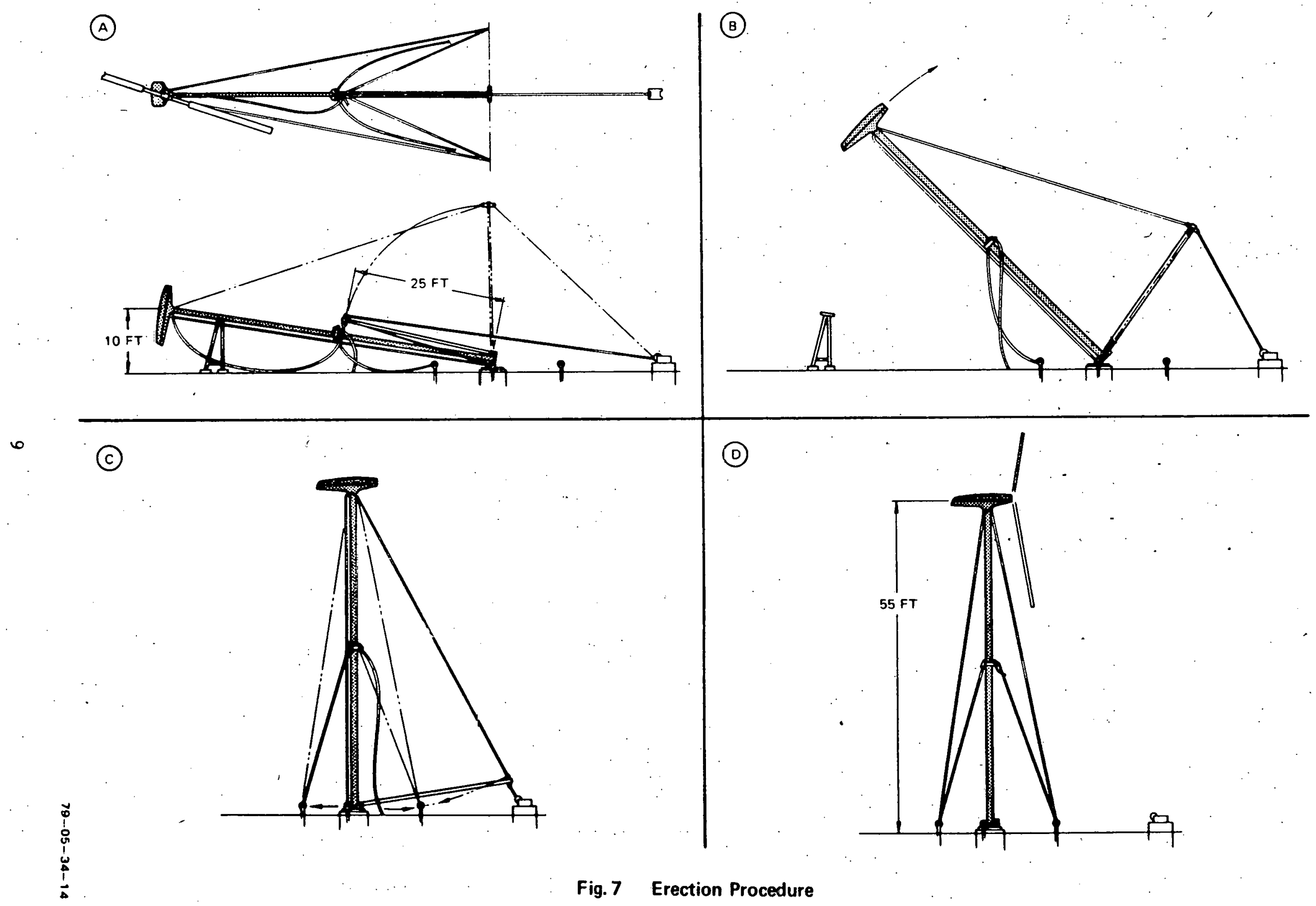


The design studies and supporting analytical efforts have shown the $8 \mathrm{~kW}$ prototype to satisfy the program objectives relative to performance and operational characteristics. Stability and loads calculations, using established helicopter aeroelastic codes, have demonstrated the system to be well damped under all loading conditions and to operate well below allowable stress levels. System costs are running about 20. percent higher than the contract goals; however reductions in the main frame and tower costs appear feasible and would be explored in a second generation $8 \mathrm{~kW}$ design. 